\title{
Estudio preliminar de anticuerpos IgG antiinsulínicos y complejos inmunitarios en pacientes colombianos con diabetes tipo 2
}

\author{
(1) Yohana Domínguez-Romero ${ }^{1}$, (1) Jorge Arturo Santa ${ }^{1}$, (D) Luisa Fernanda Bohórquez Villamizar ${ }^{2}$, \\ (D) Lucy Gabriela Delgado Murcia ${ }^{1, *}$ \\ ${ }^{1}$ Grupo de Investigación en Inmunotoxicología, Departamento de Farmacia, \\ Universidad Nacional de Colombia, Bogotá, D.C., Colombia \\ ${ }^{2}$ Facultad de Medicina, Universidad Nacional de Colombia, Bogotá, D.C., Colombia \\ Artículo de posesión para el ingreso como miembro correspondiente a la \\ Academia Colombiana de Ciencias Exactas, Físicas y Naturales el 24 de mayo de 2017
}

\begin{abstract}
Resumen
El uso terapéutico de insulina exógena de origen animal para el tratamiento de la diabetes mellitus se ha asociado con la inducción de anticuerpos antiinsulínicos, los cuales alterarían la seguridad y la eficacia de esta formulación. Con la introducción de la tecnología del ADN recombinante y la producción de insulinas con secuencias similares a la humana, se redujo, pero no se eliminó, la aparición de dichos anticuerpos. En el marco del análisis de la inmunogenicidad inducida por las proteínas terapéuticas y con el objetivo de evaluar el perfil de inmunidad humoral de tres formulaciones comerciales de insulina exógena humana (insulina regular, insulina Neutral protamine Hagedorn [NPH], e insulina glargina), se estudió la presencia de anticuerpos antiinsulínicos en 29 muestras de suero de pacientes con diabetes tipo 2, y se caracterizó su reactividad cruzada, su perfil según la subclase de IgG y su capacidad para formar complejos inmunitarios. Los pacientes se clasificaron en tres grupos según su tratamiento: a) insulina regular y NPH $(n=10)$, b) insulina NPH $(n=9)$ y c) glargina $(n=10)$. La detección, caracterización y evaluación de las subclases de IgG se hizo mediante ELISA indirecto, y la detección de complejos inmunitarios constituidos por anticuerpos antiinsulínicos e insulina exógena, mediante ELISA de captura. Los resultados permitieron evidenciar que: i) cada formulación de insulina es reconocida de manera diferencial por los anticuerpos antiinsulínicos, lo cual sugiere un mayor potencial inmunogénico de la insulina NPH y uno menor de la insulina glargina; ii) el perfil según la subclase de IgG de los anticuerpos antiinsulínicos en humanos es diferencial para cada formulación, siendo predominante la subclase IgG3 para la insulina NPH en pacientes en tratamiento con insulina regular y NPH; iii) la presencia de anticuerpos antiinsulínicos no se asoció con alteraciones de los parámetros metabólicos analizados, y iv) los complejos inmunitarios constituidos por anticuerpos antiinsulínicos e insulina exógena no se detectaron con la metodología utilizada en los sueros de los pacientes con diabetes tipo 2 estudiados. Los resultados obtenidos permiten concluir que existen diferencias entre el perfil inmunogénico de las insulinas evaluadas, lo cual es importante en el análisis de la inmunogenicidad de dichas formulaciones en cuanto a su seguridad y eficacia. (C) 2018. Acad. Colomb. Cienc. Ex. Fis. Nat.
\end{abstract}

Palabras clave: anticuerpos insulínicos; insulina exógena; complejo inmune; diabetes; ELISA.

Preliminary study of anti-insuline IgG antibodies and immune complexes in Colombian patients with type 2 diabetes

\begin{abstract}
The therapeutic use of exogenous insulin of animal origin for the treatment of diabetes mellitus has been associated with the development of insulin antibodies, which raises concerns regarding the safety and efficacy of this formulation. With the advent of recombinant DNA technology and the generation of insulin with human-like sequences, the production of insulin antibodies has been reduced but not eliminated. As part of the analysis of immunogenicity induced by therapeutic proteins and to evaluate the immunogenic profile of three commercial formulations of human exogenous insulin (regular, neutral protamine Hagedorn (NPH), and glargine) we evaluated the presence of insulin antibodies in 29 serum samples from volunteers with type 2 diabetes, and we characterized their cross-reactivity, IgG subclass profile, and ability to form immune complexes. To this end, volunteers were classified into three groups according to their current insulin therapy: a) Regular and NPH insulin (n=10); b) NPH
\end{abstract}

*Correspondencia:

Lucy Gabriela Delgado Murcia, lgdelgadom@unal.edu.co

Recibido: 30 de noviembre de 2017, Aceptado: 16 de julio de 2018, Editor: John Mario González 
$(n=9)$, and c) glargine $(n=10)$. For the detection, characterization, and evaluation of the IgG subclasses we used an indirect ELISA test, and for the detection of immune complexes formed by insulin antibodies and exogenous insulin, capture ELISA. Our results evidenced that: i) Each insulin formulation was recognized differentially by the insulin antibodies suggesting a greater immunogenic potential for NPH insulin and a lower one for glargine insulin; ii) the IgG subclasses profile of insulin antibodies in humans was different for each formulation; the IgG3 subclass for NPH insulin was predominant in volunteers treated with regular and NPH insulin; iii) the presence of insulin antibodies was not associated with alterations in the metabolic parameters analyzed, and iv) immune complexes composed of exogenous insulin antibodies were not detected in the sera of diabetic volunteers. The results obtained in this study allowed us to conclude that there are differences between the immunogenic profile of the insulin formulations tested, which has significant value in the analysis of their immunogenicity with regard to their safety and efficacy. (C) 2018. Acad. Colomb. Cienc. Ex. Fis. Nat.

Key words: Insulin antibodies; exogenous insulin; immune complexes; diabetes; ELISA.

\section{Introducción}

La Federación Internacional de Diabetes (International Diabetes Federation, IDF) reportó que en el 2017 más 425 millones de personas en el mundo padecían diabetes y 4 millones murieron a causa de la enfermedad en ese año (International Diabetes Federation, 2017). En ese mismo año, en Colombia más de 2 millones de personas padecían diabetes y más de 20 mil murieron por esta causa (International Diabetes Federation, 2017). Según la IDF, la prevalencia de diabetes tipo 2 en el 2017 fue de 7,12\% (frente a una población colombiana adulta de 29.989.290 habitantes de entre 20 y 79 años de edad). La diabetes tipo 2 es uno de los principales problemas para los sistemas de salud de Latinoamérica, ya que afecta a más de 577 millones de habitantes. El número creciente de casos en la región y la complejidad de su tratamiento han incrementado las muertes y las incapacidades resultantes. En la mayoría de los países de la región la diabetes se encuentra entre las primeras cinco causas de mortalidad por cardiopatía isquémica e infartos cerebrales. Además, es la primera causa de ceguera, enfermedad renal y amputaciones no traumáticas, así como de incapacidades prematuras, y está entre las 10 primeras causas de hospitalización y atención médica (Asociación Latinoamericana de Diabetes, 2013).

La administración de insulina exógena en pacientes con diabetes mellitus se ha asociado con la inducción de anticuerpos antiinsulínicos detectables en suero. Por lo general, estos aparecen en el paciente diabético como consecuencia del tratamiento con insulina exógena $\mathrm{y}$, al parecer, pueden afectar la correcta respuesta de disminución de los niveles de glucemia (Francis, et al., 1985; Hattori, et al., 2013).

La hipersensibilidad clínica y la resistencia a la insulina se han asociado con la presencia de anticuerpos antiinsulínicos en pacientes que han recibido terapia con insulina animal (Beeson, et al., 1956; Reeves, et al., 1982). En algún momento se pensó que la aparición de eventos de inmunogenicidad, como la generación de anticuerpos neutralizantes frente a la insulina exógena, podía deberse al uso de insulinas provenientes de otras especies distintas al humano, ya que ello permitiría su reconocimiento como antígeno. Por lo tanto, se esperaba que la producción de formulaciones con una insulina similar (en secuencia) a la humana, redujera esta probabilidad. Sin embargo, a pesar de que se disminuyeron los efectos inmunogénicos asociados a la hipersensibilidad, como la anafilaxis, las lipodistrofias y las reacciones locales graves, no se redujo totalmente la producción de anticuerpos antiinsulínicos exógenos, la cual se asoció específicamente a la respuesta inmunitaria adaptativa. En diversos estudios se ha reportado la presencia de anticuerpos antiinsulínicos en pacientes con diabetes tipo 2 tratados con insulinas recombinantes humanas y análogos de la insulina (Chen, et al., 2005; Yanai, et al., 2011; Thalange, et al., 2016; Hattori, et al., 2013). Los anticuerpos antiinsulínicos inducidos por la insulina exógena en pacientes diabéticos se ha asociado a eventos clínicos como la variabilidad de la glucemia y el control metabólico (Fineberg, et al., 2007; Segal, et al., 2008), y especialmente con la resistencia a la insulina en forma de hiperglucemia (Ishizuka, et al., 2009; Lahtela, et al., 1997) o hipoglucemia (Zhao, et al., 2010; Itoh, et al., 2011; Koyama, et al., 2005).

Independientemente de su pureza y origen, las insulinas terapéuticas continúan siendo inmunogénicas en los seres humanos por su naturaleza proteínica. Sin embargo, las respuestas inmunológicas graves son muy poco frecuentes y afectan a una minoría de los pacientes. Entre los factores que pueden favorecer la propensión a las respuestas humorales a la insulina exógena están los genéticos, la edad, la presencia de insulina exógena en altas concentraciones en la sangre y el sitio de administración del medicamento (Fineberg, et al., 2007).

Como parte del análisis de la inmunogenicidad inducida por proteínas terapéuticas de origen biotecnológico, y después de estandarizar durante el desarrollo de este trabajo las técnicas de inmunodetección de anticuerpos antiinsulínicos libres (ELISA indirecto) y de complejos inmunitarios (ELISA de captura) (Domínguez, 2014), se procedió a evaluar la presencia de dichos anticuerpos, libres y unidos a la molécula de insulina (complejo inmunitario), en muestras de pacientes con diabetes tipo 2 (cuya etiología no es autoinmunitaria y en quienes no es frecuente la generación de anticuerpos anti-insulina endógena durante el desarrollo de la enfermedad, como sí ocurre en los pacientes con diabetes tipo 1), con el fin de caracterizar su reactividad 
frente a tres formulaciones de insulina exógena (regular, NPH y glargina) y establecer su perfil según las subclases de IgG. La evaluación de los sueros de los pacientes permitió la detección y el análisis de la reactividad de los anticuerpos antiinsulínicos generados en respuesta a la administración de las insulinas exógenas evaluadas.

\section{Materiales y métodos}

Reactivos biológicos utilizados. Se utilizaron tres insulinas exógenas terapéuticas, dos humanas de origen recombinante: regular (Novo Nordisk ${ }^{\circledR}$, Bagsvaerd, Dinamarca) y NPH (Novo Nordisk ${ }^{\circledR}$, Bagsvaerd, Dinamarca), y un análogo de la insulina: glargina (Sanofi-Aventis, Frankfurt, Alemania). Estas tres distintas formulaciones se seleccionaron como blanco del estudio por estar incluidas en el Plan Obligatorio de Salud (POS) en Colombia (Comisión de regulación en salud, 2011) y por representar cada una de las categorías de la clasificación según su farmacocinética (Valla, 2010).

Obtención y almacenamiento de sueros. Las personas diabéticas voluntarias en tratamiento con insulina fueron contactadas en consulta externa por parte de dos de los autores del presente trabajo. Tres fueron los criterios de inclusión empleados: 1) voluntarios con diagnóstico de diabetes tipo 2 según los criterios de la American Diabetes Association (ADA) (American Diabetes Association, ADA, 2014); 2) voluntarios mayores de 18 años, y 3 ) voluntarios bajo tratamiento con las insulinas regular y NPH, NPH o glargina. El único criterio de exclusión fue el de padecer enfermedades del sistema endocrino e inmunológico según constancia en su historia clínica. El estudio se realizó en dos fases: i) una inicial, que contempló la toma de dos muestras de sangre, la primera en ayunas para la evaluación de la glucosa en ayunas, la hemoglobina glicosilada y la inmunodetección de anticuerpos antiinsulínicos libres, y la segunda, 120 minutos después de la ingestión de alimentos para evaluar la glucosa posprandial, y ii) una segunda fase que contempló la toma de cuatro muestras de sangre: la primera, 5 minutos antes de la administración de la insulina, y las siguientes, a los 30,60 y 120 minutos de la aplicación, con el objetivo de detectar los probables complejos inmunitarios constituidos por los anticuerpos antiinsulínicos y la insulina, y asociarlos con los valores de glucemia e insulinemia. Como sueros de control negativo se emplearon aquellos procedentes de pacientes cuya historia clínica no reportaba diabetes, inmunosupresión o endocrinopatías. Cada uno de los voluntarios (con niveles normales de glucemia o con exceso de glucosa en la sangre) tuvo conocimiento verbal y escrito del procedimiento de toma de las muestras y de su destinación según las normas de ética vigentes. Las muestras se centrifugaron a $600 \mathrm{~g}$ durante 20 minutos para la posterior recuperación del suero, el cual se dispensó en tubos de $1,5 \mathrm{ml}$ estériles (Eppendorf $囚$ ) y se almacenó a $-20^{\circ} \mathrm{C}$ hasta su empleo.

Evaluación de los niveles séricos de glucemia, insulinemia y hemoglobina glicosilada. La determinación de glucosa en las muestras de suero se hizo en el laboratorio de la Clínica de Nuestra Señora del Rosario mediante el método enzimático Glucose GOD FS (DiaSys Diagnostic Systems ${ }^{\circledR}$, Holzheim, Alemania), en tanto que los niveles séricos de insulina se evaluaron en el Laboratorio Clínico Médico Colcan utilizando la técnica de inmunoquimioluminiscencia (LIAISON®insulin, Saluggia, Italia). El porcentaje de hemoglobina glicosilada $(\% \mathrm{HbA} 1 \mathrm{c})$ se evaluó utilizando la prueba cuantitativa $\mathrm{A} 1 \mathrm{CNow}+$ (Bayer HealthCare ${ }^{\circledR}$, EE.UU.).

Ensayos inmunoabsorbentes ligados a enzimas (ELISA). Elisa indirecto para la detección de anticuerpos antiinsulínicos. Se utilizó anti-IgG humana producida en cabra (anticuerpo policlonal) acoplada a peroxidasa Invitrogen (Invitrogen ${ }^{\circledR}, C A$, USA). Para la inmunodetección de anticuerpos antiinsulínicos y sus subclases se incubó la microplaca de 96 pozos (Nunc ${ }^{\mathrm{TM}}$ Maxisorp $^{\mathrm{TM}}$ ) con $10 \mu \mathrm{g} / \mathrm{ml}$ de cada una de las formulaciones comerciales de insulina exógena en $50 \mu \mathrm{l}$ de solución tampón carbonato bicarbonato $10 \mathrm{mM}, \mathrm{pH} 9,6$, a $4{ }^{\circ} \mathrm{C}$ durante 16 horas; se lavó tres veces con solución fosfato salina (PBS) más Tween ${ }^{\circledR} 20$ (Scharlau, Barcelona, España) al 5 \% (PBS-T). Como agente bloqueador se usó leche descremada (Colanta ${ }^{\circledR}$, Funza, Colombia) al $7 \%$ y se incubó una hora a $37^{\circ} \mathrm{C}$. Posteriormente, se realizaron tres lavados y se incubó a $37^{\circ} \mathrm{C}$ durante una hora con $100 \mu \mathrm{l}$ del suero en estudio para terminar con tres lavados adicionales. Después se incubó con $100 \mu \mathrm{l}$ del anticuerpo anti-IgG conjugado con peroxidasa (Invitrogen $\AA$, Waltham, MA) en una dilución de $1 / 20.000$ en PBS-T a $37^{\circ} \mathrm{C}$ durante 1 hora, se lavó para retirar el exceso de reactivo y se adicionó el sustrato 3,3',5,5'-tetrametilbenzidina (TMB) (Invitrogen ${ }^{\circledR}$, Waltham, MA) en una proporción de 1:1 por pozo. La reacción se detuvo pasados 15 minutos con $50 \mu 1$ de $\mathrm{HCl} 1 \mathrm{~N}$. La microplaca se leyó a $450 \mathrm{~nm}$ en un lector de placas TRIAD Series Multimode Detector (Dynex ${ }^{\circledR}$ Technologies, Chantilly, VA, USA). Cada ensayo se realizó por duplicado.

Para establecer la concentración óptima de absorción de cada insulina en el pozo, se proyectó una curva de saturación con seis diluciones seriadas de cada insulina (10 a $0,078 \mu \mathrm{g} / \mathrm{ml}$ ). Las insulinas se detectaron utilizando el suero policlonal anti-insulina exógena derivado de conejo de Nueva Zelanda (producido en nuestro laboratorio con cada una de las insulinas en estudio usando adyuvante para promover la inmunogenicidad) (Domínguez, 2014). Dado que la concentración óptima de recubrimiento de la placa con el antígeno (para este caso insulina) se define como la concentración a una temperatura y un tiempo definido en los que el suero estándar o el control positivo alcanzan el mayor reconocimiento del antígeno y se obtiene el menor reconocimiento por parte del suero de control negativo y el blanco (Ochoa, 2012), se estableció el uso de $5 \mu \mathrm{g} /$ $\mathrm{ml}$ de cada formulación para la detección de anticuerpos antiinsulínicos en muestras de suero derivadas de conejos y $10 \mu \mathrm{g} / \mathrm{ml}$ para la detección de anticuerpos antiinsulínicos en muestras de suero humanas. 
Para evaluar la especificidad de la unión de antígenos y anticuerpos, se sensibilizaron pozos con albúmina de suero bovino (bovine serum albumin, BSA) y se incubaron con el suero de control positivo correspondiente a un paciente con diabetes tipo 1 en quien la generación de anticuerpos antiinsulínicos se detectó clínicamente y que había sido tratado con diversas insulinas, incluidas las tres analizadas en este estudio. En la misma placa se evaluó la unión inespecífica de anti-IgG humana en presencia de insulina y en ausencia de suero positivo para anticuerpos antiinsulínicos, revelada con anti-IgG humana acoplada a la enzima.

Elisa indirecto para la detección de las subclases de IgG. Para la detección de las subclases de $\operatorname{IgG}$ se utilizó un protocolo similar al anterior y las anti-IgG1, $\operatorname{IgG} 2$, IgG3 e IgG4 humanas producidas en ratones (anticuerpos monoclonales), marcadas con peroxidasa (Invitrogen ${ }^{\circledR}$ ) en una dilución de 1:500 en PBS durante 2 horas a $37^{\circ} \mathrm{C}$.

Elisa de captura para la detección de complejos inmunitarios. Para la detección de complejos inmunitarios constituidos por anticuerpos antiinsulínicos e insulina exógena, la microplaca de 96 pozos (Nunc ${ }^{\mathrm{TM}}$ MaxiSorp ${ }^{\mathrm{TM}}$ ) se incubó con $50 \mu \mathrm{l}$ de anticuerpos antiinsulínicos purificados del suero de los conejos previamente inmunizados (denominados anticuerpos policlonales de captura). Los anticuerpos de captura anti-insulina regular y anti-glargina (sometidos previamente a titulación) se diluyeron 1/1.200 y los anti-NPH en $1 / 100$ de solución tampón carbonato bicarbonato $0,05 \mathrm{mM}, \mathrm{pH} 9,6$. Se incubó durante 1 hora a $37{ }^{\circ} \mathrm{C}$ antes y después de la incubación a $4{ }^{\circ} \mathrm{C}$ durante 16 horas y se lavó cuatro veces con PBS-T (Scharlau, Barcelona, España). Como agente bloqueador se usó leche descremada al $5 \%$ en PBS-T, se incubó durante 1 hora a $37{ }^{\circ} \mathrm{C}$ y se lavó. Los complejos inmunitarios de control (formados in vitro en una concentración de $10,3 \mu \mathrm{g} / \mu \mathrm{l}$ ) y $50 \mu \mathrm{l}$ de las muestras de suero en estudio se incubaron en una dilución de $1 / 100$ en PBS y leche descremada al $3 \%$ durante 1 hora a $37^{\circ} \mathrm{C}$. Después del lavado, la placa se incubó con $50 \mu \mathrm{l}$ de anticuerpo anti-IgG conjugado con peroxidasa (Invitrogen ${ }^{\circledR}$ ) en una dilución de 1:25000 en PBS-T a $37^{\circ} \mathrm{C}$ durante 1 hora, y de nuevo se lavó para retirar el exceso de

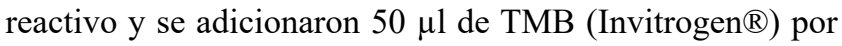
pozo. La reacción se detuvo pasados 30 minutos con $50 \mu \mathrm{l}$ de HCL 1N. La microplaca se leyó a $450 \mathrm{~nm}$ en un lector de placas Tecan GENios ${ }^{\mathrm{TM}}$ Microplate Reader (Tecan, Suiza). Cada ensayo se realizó por duplicado.

Para evaluar la especificidad del ELISA, se realizaron cuatro ensayos: i) se evaluó el sistema de inmunodetección en ausencia de anticuerpo de captura sensibilizando la placa con BSA; ii) se evaluó el reconocimiento del anticuerpo secundario (anti-IgG humana) por parte del anticuerpo de captura en ausencia de la muestra de suero; iii) se evaluó si el sistema de inmunodetección reconocía tanto la molécula de insulina como la del anticuerpo antiinsulínico de manera individual (no como parte de un complejo inmunitario), y iv) se evaluó el sistema de captura en ausencia de anti-IgG humana.
Formación in vitro de complejos inmunitarios de anticuerpos antiinsulínicos e insulina exógena. Con el fin de establecer un control positivo que permitiera comprobar que el sistema de captura estandarizado era capaz de detectar los complejos inmunitarios constituidos por anticuerpos antiinsulínicos e insulina exógena, se planteó su formación in vitro. Para ello se incubaron $366,8 \mu \mathrm{g}$ de las IgG del suero de un paciente diabético (previamente depuradas con ácido caprilico y precipitadas con sulfato de amonio) con $69,12 \mu \mathrm{g}$ de cada insulina (la formación de complejos fue independiente para cada insulina analizada). Los volúmenes de IgG e insulina incubados para la formación de los complejos se establecieron partiendo de sus molaridades, de tal manera que por cada molécula de IgG hubiera dos moléculas de insulina. Se incubó en agitación constante durante 1 hora a $37^{\circ} \mathrm{C}$ antes después de la incubación a $4{ }^{\circ} \mathrm{C}$ durante 16 horas. La confirmación de la formación in vitro de los complejos inmunitarios se hizo mediante dos corridas electroforéticas de geles de poliacrilamida al $12,5 \%$ en condiciones no desnaturalizantes y reductoras, y sus respectivos Western blot para la detección de insulina e IgG humana.

Electroforesis en condiciones desnaturalizantes y no desnaturalizantes. Para evidenciar la formación in vitro de complejos inmunitarios de anticuerpos antiinsulínicos e insulina exógena, se corrieron cuatro geles de poliacrilamida al $12,5 \%$ (dos en condiciones no desnaturalizantes y dos en condiciones desnaturalizantes y reductoras). En cada pozo se colocaron $10 \mu \mathrm{l}$ de muestra que correspondían a 103 $\mu \mathrm{g}$ de cada uno de los complejos formados in vitro por los anticuerpos antiinsulínicos y la insulina regular, la NPH y la glargina y $3 \mu \mathrm{l}$ de solución de carga de manera individual. Una réplica de los geles no desnaturalizantes y una de los geles desnaturalizantes y reductores se tiñeron con una solución de azul de Coomassie ${ }^{\circledR}$ R-250 (Merck, Alemania) disuelto en metanol y ácido acético (Merck, Alemania) durante 20 minutos y se decoloró con metanol al $40 \%$.

Las corridas electroforéticos se llevaron a cabo en cámaras de electroforesis Mini-PROTEAN ${ }($ Bio-Rad $\AA$, CA, USA). Las muestras corridas en condiciones no desnaturalizantes se mezclaron con solución de carga no desnaturalizante $(0,5 \mathrm{M}$ de Tris-HCl, $\mathrm{pH} 6,8$, glicerol, $0,5 \%(\mathrm{p} / \mathrm{v})$, azul de bromofenol y agua destilada) y las muestras corridas en condiciones desnaturalizantes y reductoras se mezclaron con solución Laemli (0,5 M Tris-HCl, pH 6,8, glicerol, 10 $\%(\mathrm{p} / \mathrm{v})$ SDS, 0,5 \% $(\mathrm{p} / \mathrm{v}))$, azul de bromofenol (Merck, Alemania) y beta-mercaptoetanol (Merck, Alemania) y se hirvieron durante 5 minutos. Los geles de electroforesis en condiciones desnaturalizantes y reductoras se corrieron a $100 \mathrm{~V}$ durante una hora a temperatura ambiente. Los geles en condiciones nativas se corrieron a $150 \mathrm{~V}$ durante 2 horas en cámara de electroforesis Mini-PROTEAN ${ }^{\circledR}$ Tetra Cell (Bio-Rad $\AA$, CA, USA).

Western blot para insulina e IgG. Para confirmar la presencia de los complejos inmunitarios formados in vitro, las réplicas del gel de poliacrilamida al 12,5\%, corrido 
en condiciones no desnaturalizantes y en condiciones desnaturalizantes y reductoras, se transfirieron a membranas de nitrocelulosa (Trans-Blot ${ }^{\circledR}$ Transfer Medium, Pure Nitrocellulose Membrane, $0.45 \mathrm{~mm}$; Bio-Rad( ${ }^{\circledR}$ ) durante 3,5 horas a $10 \mathrm{~V}$, utilizando el sistema de transferencia Trans-Blot ${ }^{\circledR}$ SD Semi-Dry Electrophoretic Transfer Cell (Bio-Rad ${ }^{\circledR}, \mathrm{CA}$, USA). Las membranas se bloquearon con leche descremada al $5 \%$ en PBS-T durante 1 hora a $37^{\circ} \mathrm{C}$. Se lavaron cuatro veces con PBS-T y, posteriormente, se incubaron a $37^{\circ} \mathrm{C}$ durante 1 hora con la mezcla de los sueros anti-insulinas exógenas de conejo (anti-regular, anti-NPH y anti-glargina) producidos en el laboratorio durante el desarrollo de este trabajo en una dilución de 1/100 en leche al $3 \%$ y PBS-T; a continuación se lavaron para retirar el exceso de anticuerpo y se incubaron durante 1 hora con anti-IgG de conejo conjugado con peroxidasa (Invitrogen $\AA$, CA, USA) en una dilución de 1/5000 en leche al $3 \%$ y PBS-T, y se lavaron y se revelaron con carbazol y peróxido de hidrógeno como sustrato; una vez aparecidas las bandas, las membranas se volvieron a lavar y se capturaron las imágenes fotográficas. Para continuar con el proceso de confirmación, las membranas se incubaron durante 1 hora con anti-IgG humana conjugada con peroxidasa (Invitrogen ${ }^{\circledR}, \mathrm{CA}$, USA) en una dilución de 1/10.000 en leche al $3 \%$ y PBS-T; posteriormente, se lavaron para retirar el exceso de anticuerpo y se revelaron con carbazol y peróxido de hidrógeno y, una vez aparecidas las bandas, las membranas se volvieron a lavar para capturar las imágenes fotográficas.

\section{Análisis de datos}

Las densidades ópticas obtenidas del control negativo utilizado en este protocolo (solo diluyente, sin suero, expresado como un promedio del duplicado), se restaron de aquellas obtenidas de las muestras de suero de los pacientes con diabetes tipo 2 y de aquellos con niveles normales de glucemia. Para determinar el valor de absorbancia a partir del cual se debe considerar la posible presencia de anticuerpos antiinsulínicos (punto de corte), se usó el promedio de las densidades ópticas obtenidas por los sueros de los voluntarios sin diabetes tipo 2 (controles negativos) frente a cada formulación, más dos desviaciones estándar (DE). Para compensar la variabilidad entre las placas, las densidades ópticas de las muestras de los pacientes con diabetes tipo 2 bajo tratamiento con insulina, se normalizaron con el promedio de aquellas de las muestras de los controles después de calcular el índice de reconocimiento, definido como el cociente de las densidades ópticas obtenidas de cada suero de los pacientes con diabetes tipo 2 (DOd) sobre la media de las de los sueros de los controles (DOc), en las que los valores superiores a 1 sugieren la presencia de anticuerpos antiinsulínicos y los menores a 1 indican la ausencia de dichos anticuerpos. Se estableció un rango de incertidumbre entre 0,8 y 1,2 .

$$
\mathrm{IR}=\mathrm{DOd} / \mathrm{DOc}
$$

Los datos se analizaron usando el programa estadístico GraphPad Prism ${ }^{\circledR}$, versión 5.0 (GraphPad Software, USA). Se utilizó estadística descriptiva no paramétrica para detallar las características de los grupos experimentales. Mediante la prueba Anova de una vía se compararon los grupos experimentales, y la prueba de Bonferroni se usó para los índices de reconocimiento, los niveles de glucemia en ayunas y después de ingerir alimento y para el $\% \mathrm{HbA} 1 \mathrm{C}$. Los resultados se consideraron significativos cuando $\mathrm{p}$ fue menor de 0,05 .

\section{Consideraciones éticas}

Según las categorías establecidas en el Artículo 11 de la Resolución 008430 de 1993, del Ministerio de Salud, este trabajo de investigación se clasificó como investigación de riesgo mínimo, ya que se emplearon datos obtenidos a través de procedimientos comunes como exámenes de laboratorio y de tratamientos rutinarios como la extracción de sangre por punción venosa en adultos en buen estado de salud, con frecuencia máxima de dos veces a la semana, y la administración de insulina como medicamento de uso común con dosis y vías de administración medicamente establecidas. El profesional a cargo explicó a todos los participantes el procedimiento al que se les sometería y estos firmaron el consentimiento informado. La formación de anticuerpos antiinsulínicos en conejos de laboratorio se indujo siguiendo las pautas estrictas para el cuidado y la manipulación de los animales; además, se observó un adecuado manejo del material de riesgo biológico. El trabajo contó con el aval del Comité de Ética de la Facultad de Ciencias de la Universidad Nacional (Acta 08 del 12 de diciembre de 2011).

\section{Resultados}

Caracterización de los grupos experimentales. Con el ánimo de caracterizar los grupos experimentales definidos para la detección de anticuerpos antiinsulínicos, los 29 pacientes con diabetes tipo 2 se clasificaron en tres grupos según su tratamiento: i) insulina regular y NPH, ii) NPH y iii) glargina. Se analizaron los datos obtenidos de sus historias clínicas y los parámetros bioquímicos evaluados en sus muestras de suero. En primera instancia, se analizó la edad, el sexo y el índice de masa corporal (IMC), y no se encontraron diferencias estadísticamente significativas para la edad y el sexo, aunque sí un aumento en el IMC, siendo este mayor en el grupo tratado con insulina regular y NPH y menor en los tratados con NPH (Tabla 1), aunque sin una diferencia estadísticamente significativa. Al evaluar las variables relacionadas con el diagnóstico y el tratamiento de la diabetes: tiempo de diagnóstico, tiempo del tratamiento con insulina y dosis diaria, se encontró que el grupo tratado con la mezcla de insulina regular y NPH registró los valores más altos en las variables mencionadas (Tabla 1) sin ser esta asociación estadísticamente significativa. Al analizar los parámetros bioquímicos: porcentaje de 
Tabla 1. Características generales y parámetros metabólicos de los pacientes con diabetes tipo 2 según su tratamiento con insulina

\begin{tabular}{|c|c|c|c|c|}
\hline \multirow[t]{3}{*}{ Variables } & \multirow[b]{2}{*}{ Total } & \multicolumn{3}{|c|}{ Tratamiento } \\
\hline & & Regular y NPH & NPH & Glargina \\
\hline & $\mathrm{n}=29$ & $\mathrm{n}=10$ & $\mathrm{n}=9$ & $\mathrm{n}=10$ \\
\hline Edad (años) & $54,6(16,3)^{*}$ & $58,0 \quad(21,3)$ & $49,4(17,3)$ & $55,7 \quad(8,0)$ \\
\hline Sexo $(M / F)$ & $17 / 12$ & $6 / 4$ & $5 / 4$ & $6 / 4$ \\
\hline Índice de masa corporal $\left(\mathrm{Kg} / \mathrm{m}^{2}\right)$ & $28,3 \quad(4,7)$ & $25,8 \quad(3,3)$ & $31,5 \quad(5,9)$ & $28,0 \quad(2,9)$ \\
\hline Diagnóstico de diabetes (años) & $14,0 \quad(9,0)$ & $19,4 \quad(10,9)$ & $9,4 \quad(7,0)$ & $12,8 \quad(5,8)$ \\
\hline Tiempo de tratamiento con insulina (años) & $6,0 \quad(4,6)$ & $10,4 \quad(4,0)$ & $3,5 \quad(2,7)$ & $4,1 \quad(5,0)$ \\
\hline Dosis total de insulina (UI/d) & $38,5 \quad(17,2)$ & $46,1 \quad(24,0)$ & $36,8(13,0)$ & $27,8 \quad(9,9)$ \\
\hline $\operatorname{HbA1C}(\%)$ & $9,1 \quad(2,2)$ & $9,2 \quad(2,4)$ & $8,8 \quad(1,8)$ & $9,2 \quad(2,4)$ \\
\hline Glucemia pre (mg/dl) & $165,6 \quad(92,9)$ & $184,2(143,2)$ & $142,4(35,9)$ & $167,7 \quad(65,2)$ \\
\hline Glucemia post (mg/dl) & $248,4(116,9)$ & $239,0(142,7)$ & $213 \quad(91,8)$ & $289,1(107,2)$ \\
\hline
\end{tabular}

*Los datos representan la media \pm la desviación estándar

hemoglobina glicosilada (\%HbA1C), glucemia en ayunas (glucemia pre) y 120 minutos después de la ingestión de alimentos (glucemia post), no se encontraron diferencias estadísticamente significativas entre los grupos (Tabla 1). El porcentaje de hemoglobina glicosilada fue mayor a 8 en todos los grupos, lo que permitió clasificar a los pacientes como no controlados.

Inmunodetección y caracterización de la reactividad de los anticuerpos antiinsulínicos. Con el fin de detectar los anticuerpos antiinsulínicos y caracterizar su reactividad frente a tres formulaciones comerciales de insulina humana, se evaluó en cada muestra de suero la presencia de anticuerpos antiinsulínicos mediante ELISA indirecto. Para establecer a partir de qué densidad óptica se registraba el reconocimiento positivo de anticuerpos antiinsulínicos, se estableció un punto de corte para cada formulación correspondiente al promedio de las densidades ópticas obtenidas de 10 sueros de los controles, más la suma de dos desviaciones estándar. El punto de corte para los sueros reactivos frente a las insulinas regular, NPH y glargina fue de 0,270, 0,346 y 0,256, respectivamente (Figura 1 A-C). Según los resultados, en 20 de los sueros de los 29 pacientes con diabetes tipo 2 en tratamiento con insulina, se reconoció al menos una de las insulinas evaluadas, lo cual sugirió la presencia de anticuerpos antiinsulínicos en 68,9\% de los pacientes. Además, se encontró que siete sueros $(70 \%)$ del grupo tratado con la mezcla de insulina regular y NPH reconocieron la insulina regular y nueve (90\%), la insulina NPH (Figura 1 A y B, respectivamente), evidenciando un reconocimiento preferencial de la insulina NPH. Por otro lado, en el grupo tratado con NPH, siete sueros $(77,7 \%)$ reconocieron esta misma formulación (Figura 1B) $\mathrm{y}$ en el grupo tratado con glargina, cuatro sueros (40\%) reconocieron la insulina glargina (Figura $1 \mathrm{C}$ ).

Para caracterizar la reactividad de los anticuerpos antiinsulínicos frente a las tres insulinas analizadas y asociarla con el tratamiento que recibían los pacientes, se normalizaron las densidades ópticas de cada voluntario diabético con el promedio de aquellas de los sueros de los controles calculando el índice de reconocimiento. El reconocimiento de la insulina NPH fue mayor y altamente significativo en los individuos tratados con la combinación de insulina regular e insulina NPH (Figura 1D). Llama la atención que esto no sucedió en el grupo tratado con NPH y, aunque se observó un reconocimiento preferencial por este tipo de insulina, los datos obtenidos no fueron estadísticamente significativos (Figura $1 \mathrm{E}$ ). Al analizar los índices de reconocimiento obtenidos para cada formulación, se observó el reconocimiento cruzado de la insulina NPH y la insulina regular en cinco sueros (55\%) de los tratados y la glargina en dos sueros $(22,2 \%)$, aunque este no fue significativo (Figura $1 \mathrm{E}$ ). A pesar de que el grupo tratado con glargina presentó índices de reconocimiento más bajos que los obtenidos en los demás grupos experimentales, se evidenció un leve, aunque no significativo, reconocimiento de la NPH y la insulina regular, en tanto que fue muy bajo para la glargina (Figura $1 \mathrm{~F}$ ).

Evaluación del perfil de las subclases de IgG de los anticuerpos antiinsulínicos en pacientes con diabetes tipo 2. Como parte de la caracterización de los anticuerpos antiinsulínicos, se evaluó el perfil de subclases de IgG para cada insulina mediante un ELISA indirecto. Los resultados obtenidos se analizaron calculando los índices de reconocimiento de las subclases de IgG para cada insulina (regular, NPH y glargina). Para analizar el efecto del tratamiento con insulina sobre el perfil de las subclases de IgG, los datos obtenidos se graficaron según el tratamiento que estuvieran recibiendo los pacientes (Figura 2), lo que permitió observar que los anticuerpos antiinsulínicos presentes en los sueros del grupo tratado con la mezcla de insulinas regular y NPH fueron predominantemente de la subclase IgG3 (Figura 2 D).

Formación in vitro de complejos inmunitarios de anticuerpos antiinsulínicos e insulina exógena. Para evidenciar la presencia de complejos inmunitarios después de la incubación de cada insulina con IgG purificadas, se corrieron 
cuatro geles de poliacrilamida al 12,5\%: dos en condiciones no desnaturalizantes y dos en condiciones desnaturalizantes y reductoras (Figura 3A y 3D, respectivamente). Uno de los geles no desnaturalizantes y uno de los desnaturalizantes y reductores se tiñeron con azul de Coomassie y ello evidenció una banda a la altura de los $150 \mathrm{kDa}$ compatible con la masa molecular de la inmunoglobulina G (IgG) (Huber, 1980) para el primer caso en los cuatro carriles (carril 1: anticuerpos antiinsulínicos e insulina regular; carril 2: anticuerpos antiinsulínicos y NPH; carril 3: anticuerpos antiinsulínicos y glargina, y carril 4: anticuerpos antiinsulínicos únicamente). Cabe destacar que en el carril 3 se evidenció una banda de 6 $\mathrm{kDa}$, aproximadamente, compatible con la masa molecular de la insulina, en este caso, la glargina (Figura 3A). El hecho de que en el gel no reductor donde se sembraron los complejos formados por los anticuerpos antiinsulínicos y la insulina regular y los anticuerpos antiinsulínicos y la NPH (carriles 1 y 2, respectivamente), solo se evidenció una banda a la altura de los $150 \mathrm{kDa}$, lo cual sugiere la posible formación de complejos inmunitarios, ya que de no ser así, se esperaría que corrieran la banda de IgG (banda de $150 \mathrm{kDa}$ ) y de insulina (banda de $6 \mathrm{kDa}$ ) por separado, como se evidenció en el carril 3, en el cual se colocó el complejo formado por los anticuerpos antiinsulínicos y la glargina (Figura 3A). Aunque en este caso se evidenció la banda de insulina (anticuerpos antiinsulínicos y glargina), no se descarta la formación de complejos inmunitarios. La ausencia de la banda de $6 \mathrm{kDa}$ en los carriles 1 y 2 podría deberse a la salida de la insulina del gel durante la corrida electroforética, sin embargo, esto es poco probable teniendo en cuenta que el tiempo y el voltaje aplicados se estandarizaron para evitar la salida de la insulina del gel.

En el gel corrido en condiciones desnaturalizantes y reductoras se observaron tres bandas en los carriles 1 a 3 , las primeras a la altura de los 55 y los $25 \mathrm{kDa}$ (Huber, 1980), y la última a la altura de los $6 \mathrm{kDa}$, aproximadamente, datos compatibles con las masas moleculares de las cadenas pesadas y livianas de la IgG y de la insulina, respectivamente (Figura 3D). En el carril 4 de este gel solo se observaron las primeras bandas a la atura de los 55 y los $25 \mathrm{kDa}$, resultado que se esperaba, ya que en este carril solo se colocó la IgG. Los resultados obtenidos tanto en el gel no desnaturalizante como en el desnaturalizante y reductor sugieren la formación de complejos inmunitarios con las insulinas regular y $\mathrm{NPH}$,

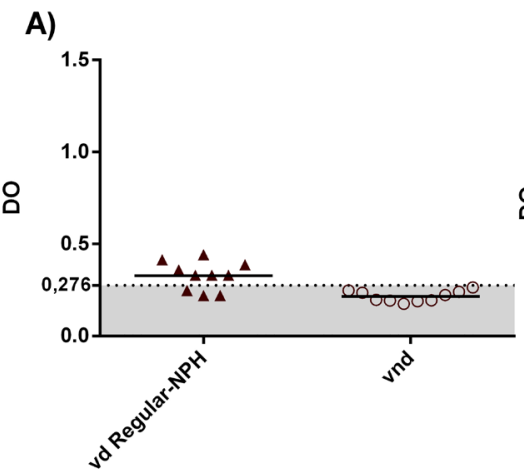

D)

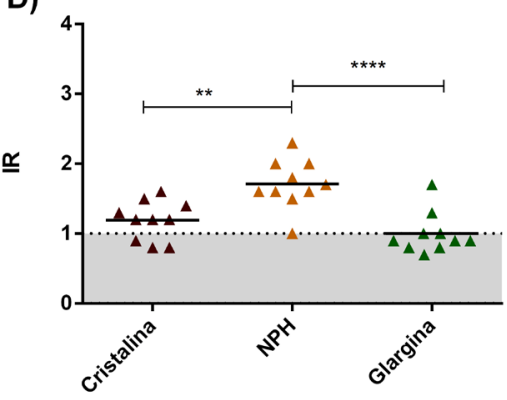

B)

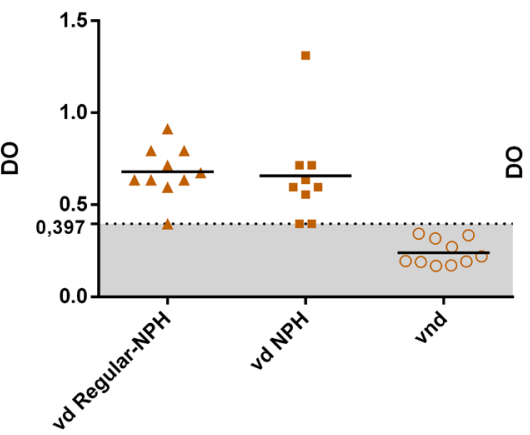

E)

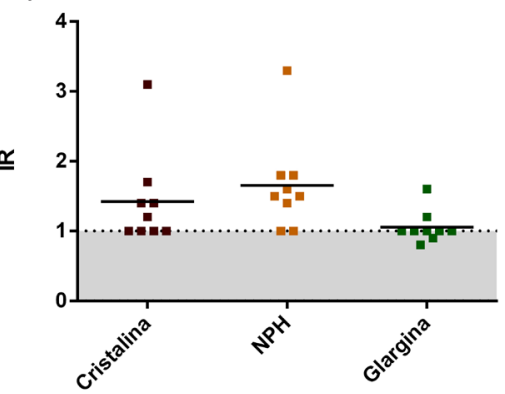

C)

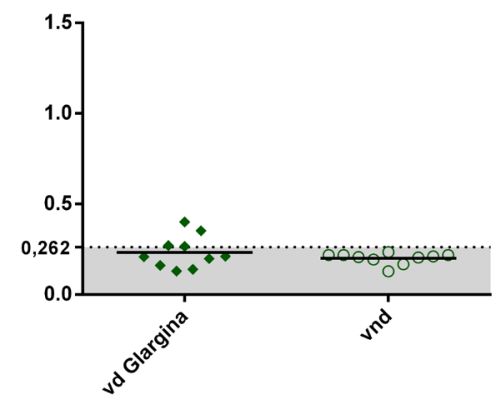

F)

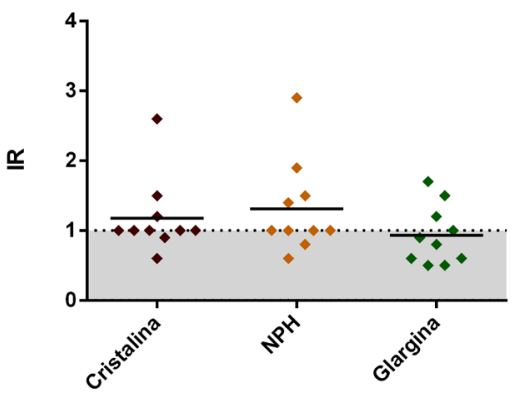

Figura 1. Inmunodetección de anticuerpos antiinsulínicos y caracterización de su reactividad frente a tres formulaciones de insulina exógena humana. Mediante métodos inmunológicos se detectaron anticuerpos antiinsulínicos en sueros de pacientes con diabetes tipo 2 tratados con las insulinas: A) regular y NPH, B) regular y NPH y NPH, y C) glargina, los cuales se evaluaron frente a las insulinas: A) regular, B) NPH y C) glargina. La reactividad de los anticuerpos antiinsulínicos frente a las tres formulaciones evaluadas también se graficó usando el índice de reconocimiento calculado para los pacientes tratados con las insulinas: D) regular y NPH, E) NPH y F) glargina, y se evaluaron frente a las insulinas regular, NPH y glargina tomadas individualmente. Los ensayos se hicieron por duplicado en tres ocasiones y muestran la desviación estándar para cada punto. Las gráficas de la $\mathbf{A}$ a la $\mathbf{C}$ muestran la media de las densidades ópticas para cada grupo experimental y el punto de corte para cada insulina evaluada. Las gráficas de la $\mathbf{D}$ a la $\mathbf{F}$ muestran la media de los índices de reconocimiento para cada grupo experimental y cada insulina evaluada. Se presenta un ensayo representativo realizado por duplicado, con la media y los valores individuales. Vd: Voluntarios diabéticos; Vnd: voluntarios no diabéticos. 

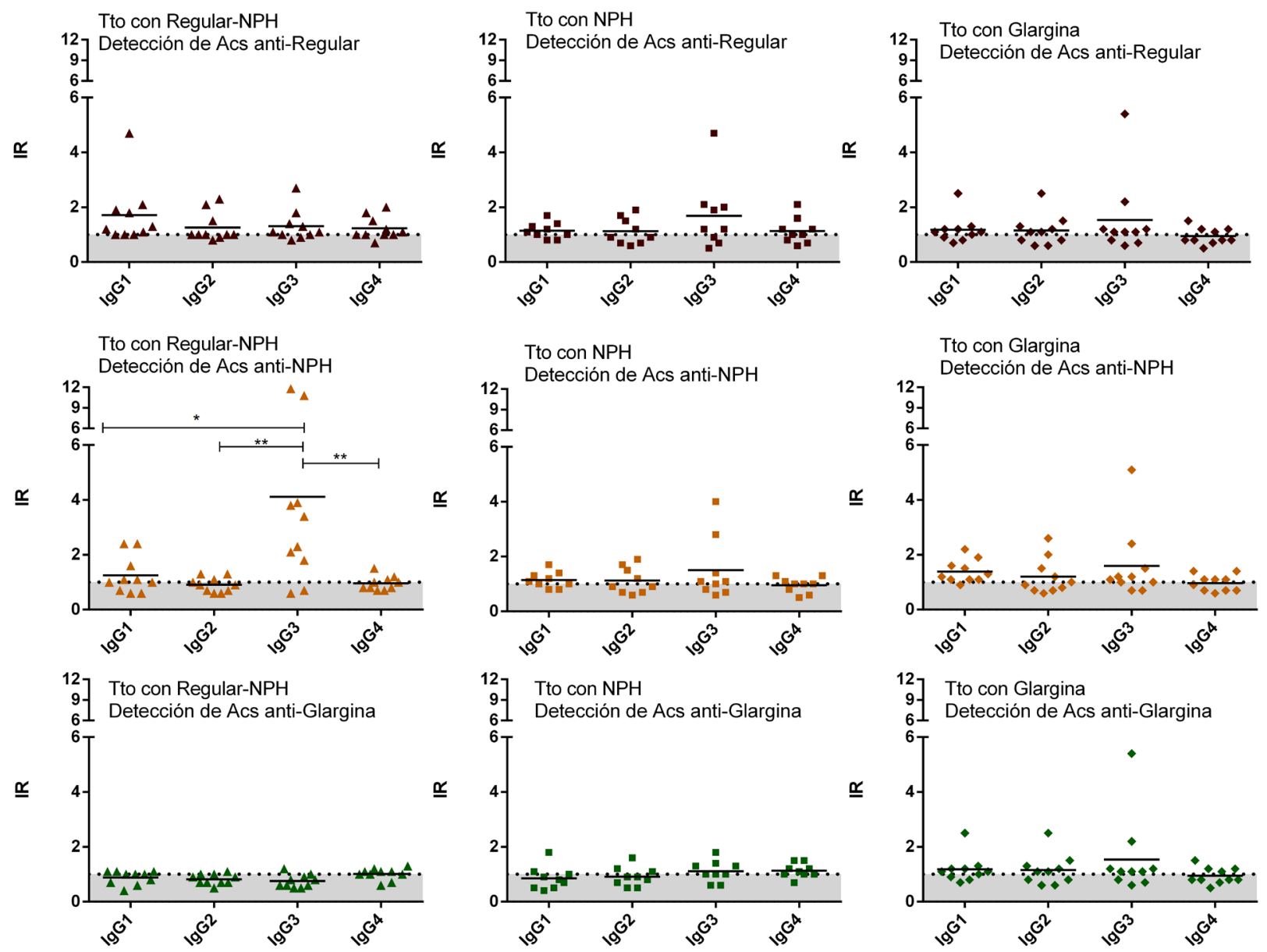

Figura 2. Perfil de las subclases de IgG de los anticuerpos antiinsulínicos según el tratamiento con insulina que recibían los pacientes y para las tres formulaciones de insulina analizadas. A) Pacientes en tratamiento con insulina regular y NPH evaluados para la insulina regular. B) Pacientes en tratamiento con insulina NPH y evaluados para la insulina regular. C) Pacientes en tratamiento con insulina glargina y evaluados para la insulina regular. D) Pacientes en tratamiento con insulina regular y NPH evaluados para insulina NPH. E) Pacientes en tratamiento con insulina NPH evaluados para insulina NPH. F) Pacientes en tratamiento con insulina glargina evaluados para insulina NPH. G) Pacientes en tratamiento con insulina regular y NPH evaluados para la insulina glargina. $\mathbf{H}$ ) Pacientes en tratamiento con insulina NPH evaluados para insulina glargina. I) Pacientes en tratamiento con insulina glargina evaluados para insulina glargina. Cada punto representa el índice de reconocimiento de una muestra contra la subclase de IgG analizada. Los ensayos se hicieron por duplicado en dos experimentos diferentes. Se muestra la media del grupo y los valores individuales (promedio del duplicado de cada paciente). Tto: tratamiento

ya que en condiciones no desnaturalizantes solo se observó la banda a la altura de los $150 \mathrm{kDa}$, en tanto que en condiciones desnaturalizantes (temperatura de ebullición) y reductoras (presencia de $\beta$-mercaptoetanol), se observaron tres bandas compatibles con las masas moleculares de la insulina y las cadenas livianas y pesadas de las IgG.

Para confirmar los resultados obtenidos en los geles de electroforesis, los cuales sugerían la formación in vitro de complejos inmunitarios, se transfirieron sus réplicas a membranas de nitrocelulosa y se revelaron en un primer momento con anticuerpos antiinsulínicos producidos en conejo (anti-regular, anti-NPH y anti-glargina), como se muestra en la Figura 3B y 3E, y en un segundo momento se revelaron con anti-IgG humana como se muestra en la figura $3 \mathrm{C}$ y $3 \mathrm{~F}$, lo cual evidenció la presencia de insulina a la altura de los $150 \mathrm{kDa}$ en la membrana en condiciones no desnaturalizantes (Figura 3B) y a la altura de los 55, 25 y $6 \mathrm{kDa}$ en la membrana y en condiciones desnaturalizantes y reductoras, en los carriles 1 a 3 (Figura $3 \mathrm{E}$ ). Cuando se reveló con anti-IgG humana se intensificaron las bandas observadas a la altura de los $150 \mathrm{kDa}$ en condiciones no desnaturalizantes, y a la altura de los 55 y los $25 \mathrm{kDa}$ en condiciones desnaturalizantes y reductoras. Estos resultados confirman la formación in vitro de complejos inmunitarios de anticuerpos antiinsulínicos e insulina exógena (en el caso de las tres insulinas analizadas), y sugieren su posible uso como control positivo en el ELISA de captura.

Detección de complejos inmunitarios (anticuerpos antiinsulínicos e insulina exógena) en pacientes con diabetes tipo 2. Aunque la circulación de anticuerpos antiinsulínicos 
A)
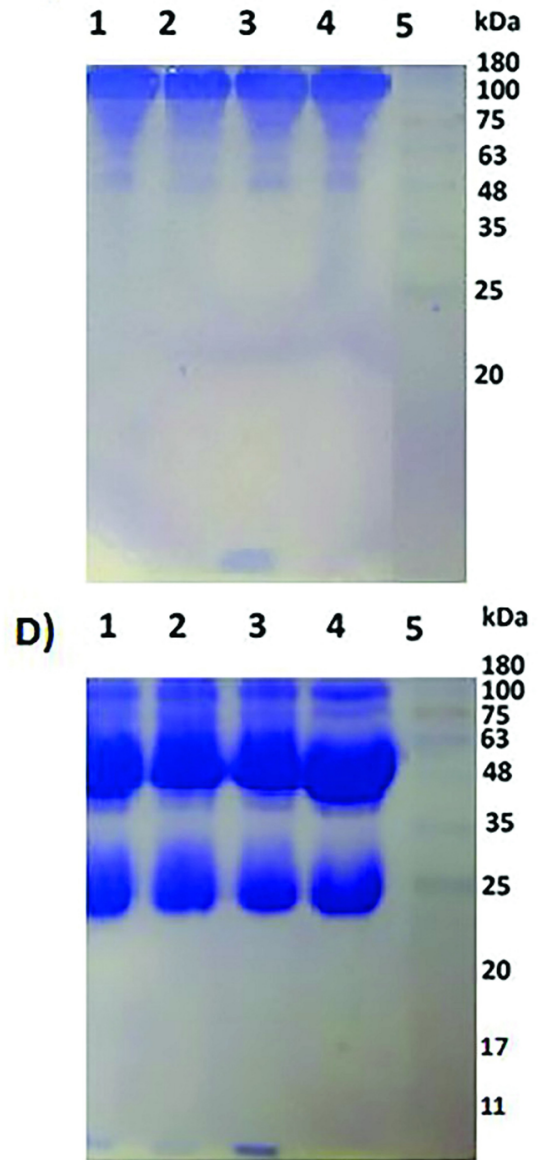

B)

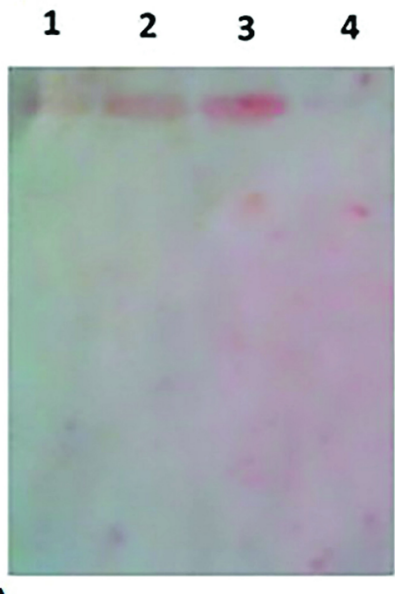

E)

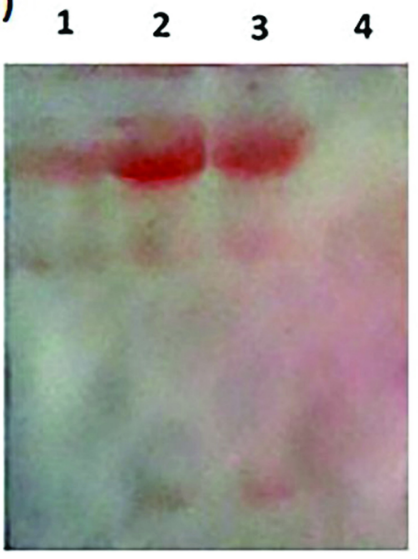

C)

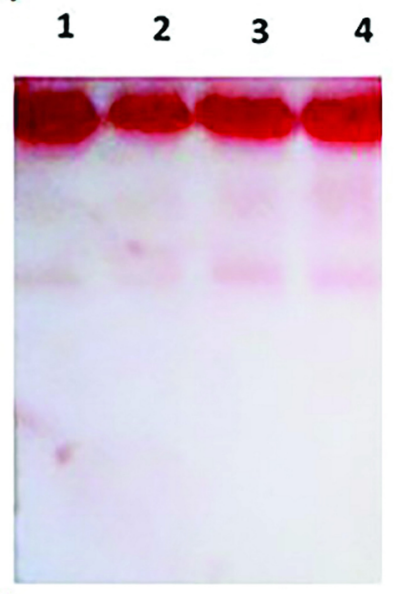

F)
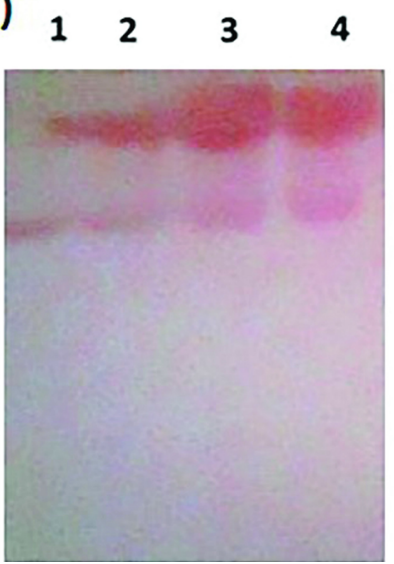

Figura 3. Formación in vitro de complejos inmunitarios de anticuerpos antiinsulínicos-e insulina exógena. La evaluación de los complejos formados in vitro se hizo mediante: A) gel de electroforesis al 12,5\% en condiciones no desnaturalizantes; B) Western blot para la inmunodetección de insulina en condiciones no desnaturalizantes; C) Western blot para la inmunodetección de IgG en condiciones no desnaturalizantes; D) gel de electroforesis al 12,5\% en condiciones desnaturalizantes y reductoras; E) Western blot para la inmunodetección de insulina en condiciones desnaturalizantes y reductoras, y F) Western blot para la inmunodetección de IgG en condiciones desnaturalizantes y reductoras. Carril 1: complejos formados in vitro por anticuerpos antiinsulínicos e insulina regular; carril 2: por anticuerpos antiinsulínicos e insulina NPH; carril 3: por anticuerpos antiinsulínicos e insulina glargina; carril 4: anticuerpos antiinsulínicos, y el carril 5 corresponde al patrón de masa molecular. Las fotografías se tomaron de un ensayo representativo.

y su correspondiente antígeno (insulina exógena) favorecen la formación de complejos inmunitarios que pueden mantenerse en circulación durante largos periodos y acumularse en vasos sanguíneos pequeños, hasta el momento ello no se ha evidenciado como relevante y en muy pocos casos se ha reportado la aparición de microangiopatías y complicaciones secundarias en la diabetes (Irvine, et al., 1978). En este estudio se estandarizó y se evaluó un sistema para la detección de tales complejos inmunitarios mediante ELISA de captura, con el fin de analizar la capacidad de formación de complejos inmunitarios de los anticuerpos antiinsulínicos e insulina exógena. Las muestras de suero se evaluaron en cuatro puntos de tiempo: 1) en ayuno y antes de administrar el tratamiento con insulina (0 minutos); 2) 30 minutos después de administrar la insulina y de haber ingerido alimento (30 minutos); 3) una hora después de administrada la insulina
(60 minutos), y 4) dos horas después de administrada la insulina (120 min). Con el fin de determinar a partir de cuál densidad óptica se registraba la presencia de un complejo inmunitario, se estableció un punto de corte para cada sistema, correspondiente al promedio de las densidades ópticas obtenidas de los diez sueros de los controles más la suma de dos desviaciones estándar. Así, el punto de corte para el sistema de detección de complejos formados por anticuerpos antiinsulínicos e insulina regular, NPH y glargina fue de 0,194 (Figura 4A), 0,178 (Figura 4B y 4C) y 0,165 (Figura 4D), respectivamente. Los resultados obtenidos permitieron establecer que en ninguna de las muestras de los pacientes bajo tratamiento con insulina se detectaron complejos, lo cual puede deberse a que pocos, o ninguno, se forman en condiciones naturales, a la gran efectividad de un proceso natural de depuración, o a la poca sensibilidad del sistema 

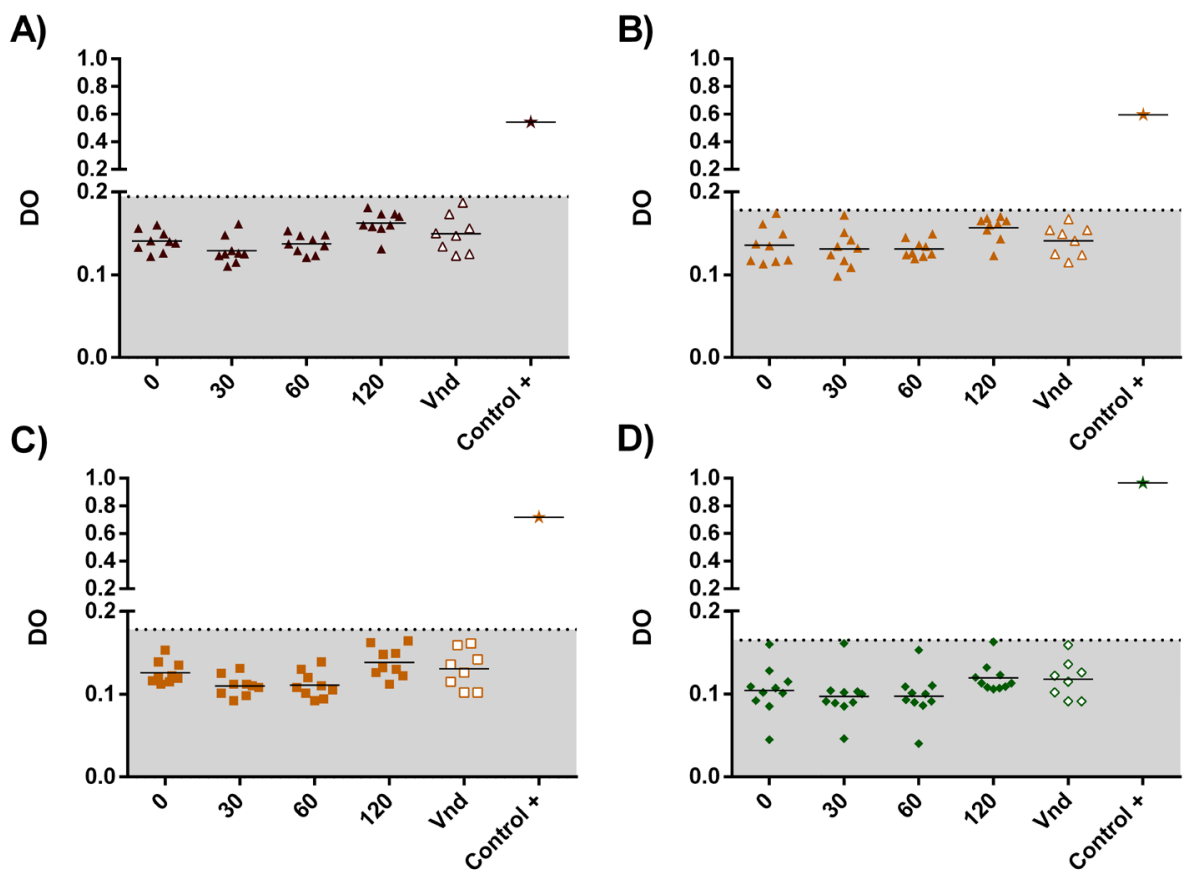

Figura 4. Inmunodetección de complejos inmunitarios antes y después de la administración de insulina exógena. A) Grupo en tratamiento con insulinas regular y NPH evaluado mediante la detección de complejos constituidos por anticuerpos antiinsulínicos e insulina regular. B) Grupo tratado con insulinas regular y NPH evaluado mediante la detección de complejos constituidos por anticuerpos antiinsulínicos y NPH. C) Grupo en tratamiento con insulina NPH evaluado mediante la detección del complejo constituido por anticuerpos antiinsulínicos y NPH. D) Grupo en tratamiento con insulina glargina evaluado mediante la detección del complejo constituido por anticuerpos antiinsulínicos y glargina. Las gráficas muestran la media de las densidades ópticas versus el tiempo en el que se tomó la muestra de los pacientes con diabetes tipo 2, así como del grupo de voluntarios no diabéticos y del control positivo (complejos formados in vitro), y la línea de corte para cada sistema de detección. Se presenta un ensayo representativo realizado por duplicado, y la media y los valores individuales. Vnd: voluntarios no diabéticos

de detección empleado en este estudio. Debe señalarse que más allá de otorgarle relevancia a los complejos inmunitarios, en este estudio se pretendió demostrar si hay algún tipo de insulina exógena que se relacione más con la formación de dichos complejos, los que, sometidos al posterior análisis de avidez y afinidad, permitirían comprender mejor los casos de poca eficacia de la insulina exógena, así como la relación entre dichos complejos y la hipoglucemia (fulminante en algunos casos) (Zhao, et al., 2010; Itoh, et al., 2011; Koyama, et al., 2005)

Análisis de los valores de glucemia e insulinemia antes y después de la administración de insulina exógena. Se tomó una muestra de sangre de cada paciente diabético en cuatro puntos de tiempo: 1) en ayuno y antes de administrar el tratamiento con insulina; 2) 30 minutos después de la administración de la insulina y de haber ingerido alimento; 3) 60 minutos después de administrada la insulina, y 4) 120 minutos después de administrada la insulina.

Los niveles de glucemia cuantificados en las cuatro muestras tomadas del grupo tratado con las insulinas regular y NPH registraron un leve aumento en los niveles de glucosa a los 30 minutos de administrado el alimento y disminuyeron levemente a los 120 minutos (Figura 5A). Estos niveles aumentaron con los niveles de insulina pasados 30 minutos y se mantuvieron hasta los 120 minutos (Figura 5D); fueron compatibles con la farmacocinética descrita para la insulina regular (acción rápida) y la insulina NPH (acción intermedia) (Eyzaguirre, et al., 2006).

La curva de glucosa del grupo en tratamiento con NPH registró la mayor concentración a los 60 minutos, la cual declinó brevemente al terminar los 120 minutos (Figura 5B). Estos resultados se asociaron con el inicio de la acción que ha sido reportado para la insulina NPH (insulina de acción intermedia). La curva de insulina para la mayoría de los pacientes del grupo tuvo un perfil similar, cuyo valor máximo se registró en los primeros 60 minutos y se mantuvo hasta los 120 minutos (Figura 5E). Estos datos se asocian con la farmacocinética de la insulina NPH, cuya acción se inicia una hora después de la administración con pico entre las 4 y las 10 horas (Eyzaguirre, et al., 2006).

Los niveles de glucosa más altos de la curva para el grupo tratado con glargina se detectaron aproximadamente a los 60 minutos y comenzaron a declinar levemente al llegar a los 120 minutos (Figura 5C), datos que se asocian con los niveles de insulina, los cuales se mantuvieron constantes pasados los 60 minutos en la mayoría de los individuos de este grupo (Figura 5F). Aunque no se obtuvieron datos después de los 120 minutos de la administración de la insulina, el 

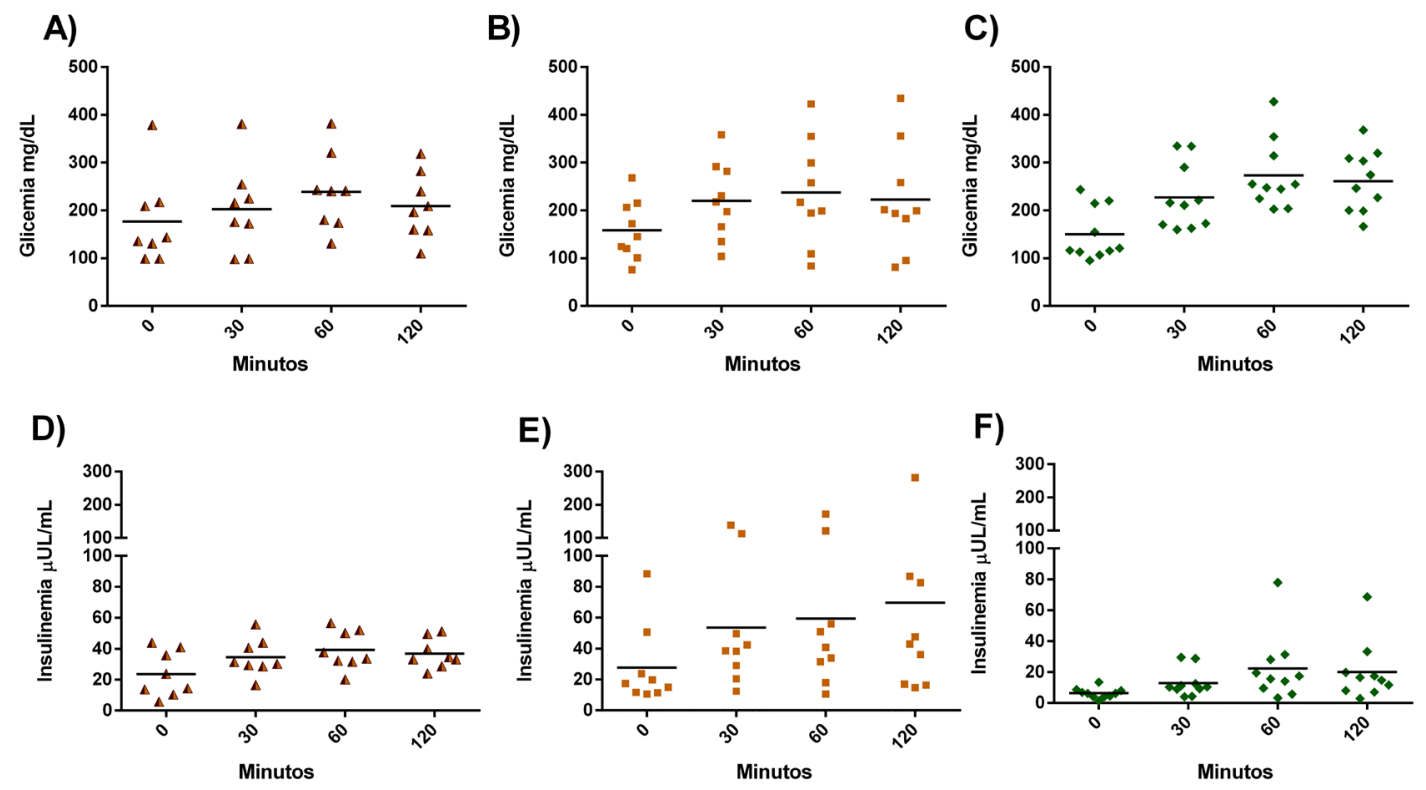

Figura 5. Glucemia e insulinemia antes y después de la administración de insulina exógena. Se cuantificaron los niveles de glucemia e insulinemia en las muestras de suero tomadas en cuatro puntos de tiempo: 1) en ayuno y antes de administrar la insulina (minuto 0); 2) 30 minutos después de administrar la insulina y de haber ingerido alimento (30 minutos); 3) 60 minutos después de administrar la insulina (60 minutos), y 4) 120 minutos después de administrar la insulina (120 minutos). A y D) Grupo tratado con las insulinas regular y NPH. B y E) Grupo tratado con la insulina NPH. C y F) Grupo tratado con la insulina glargina. Las gráficas muestran la media y los valores individuales.

perfil de la gráfica corresponde a la farmacocinética de la insulina glargina, cuya acción es prolongada y se inicia a la hora y media sin presentar oscilaciones (Vajo, et al., 2001).

\section{Discusión}

Según los resultados obtenidos, el $68,9 \%$ de los sueros de pacientes con diabetes tipo 2 bajo tratamiento con insulina reconocieron, como mínimo, una de las insulinas analizadas, lo cual sugiere la presencia de anticuerpos antiinsulínicos. Estos datos contrastan con los obtenidos en grupos experimentales de pacientes con diabetes tipo 1 tratados con insulinas humanas recombinantes, en quienes se reportan prevalencias entre 14 y $44 \%$ de anticuerpos antiinsulínicos (Schernthaner, et al., 1983; Heding, et al., 1984). Las diferencias encontradas podrían atribuirse a características propias de la técnica o a las de la población analizada en cada estudio. Los datos reportados en estudios previos se obtuvieron empleando el radioinmunoensayo, técnica capaz de detectar títulos de anticuerpos antiinsulínicos más bajos que el ELISA (Dib, et al., 1994; Sodoyez, et al., 1988). Podría plantearse, asimismo, que las diferencias entre este estudio y los reportes previos estarían relacionadas con la etiología de la diabetes de tipo 1 y la de tipo 2 , ya que los estudios anteriores se hicieron en pacientes con diabetes tipo 1 en tanto que en este se trataba de pacientes con la de tipo 2 .

Cabe mencionar que nuestros resultados evidenciaron un reconocimiento elevado de los sueros de los pacientes tratados con NPH (ya fuera mezclada con insulina regular o sola), y uno muy bajo de los sueros de los pacientes tratados con glargina frente a las insulinas analizadas, lo cual sugeriría un mayor potencial inmunogénico de la insulina NPH comparada con la glargina. En el caso de la insulina NPH, la presencia de moléculas de protamina (un péptido catiónico de 5.000 daltons rico en arginina) en su formulación podría ser una de las variables favorecedoras de su perfil inmunogénico. La protamina se ha relacionado con la producción de inmunoglobulinas IgG e IgE después de la administración intravenosa de una dosis única (Nyhan, et al., 1996; Weiss, et al., 1989). En cuanto al bajo reconocimiento de los anticuerpos antiinsulínicos por la glargina, se ha sugerido que modificaciones en la secuencia aminoacídica de la insulina, como la adición de dos argininas en las posiciones 31 y 32 de la cadena $\mathrm{B}$ y el reemplazo de ácido aspártico por una glicina en la posición 21 de la cadena A, disminuyen su potencial inmunogénico, ya sea directamente (eliminado epítopes inmunogénicos) o indirectamente (modificando su farmacocinética). Los datos aquí obtenidos concuerdan con reportes previos sobre la poca inmunogenicidad de la formulación de la glargina, con la cual los pacientes tratados por más de un año no reflejan un aumento en la producción de anticuerpos antiinsulínicos (Pieber, et al., 2000).

Otro dato interesante es la diferencia entre el reconocimiento de los sueros de los individuos tratados con la combinación de insulina regular y NPH (mayor y altamente significativo) y los sueros de los individuos tratados con la insulina NPH (menor y no significativo) frente a la insulina NPH, lo cual podría deberse a varias situaciones: 1) la formación de nuevos epítopes en la mezcla de insulina regular y NPH que potencializarían la inmunogenicidad de 
NPH; 2) el tiempo prolongado del tratamiento con insulina del grupo tratado con regular y NPH, ya que cuanto mayor es la exposición al antígeno (insulina exógena) mayor es la probabilidad de que aumente la afinidad y, por ende, la especificidad de los anticuerpos antiinsulínicos, y 3) la mayor dosis de insulina administrada en este grupo, situación que condiciona la respuesta inmunitaria frente a este potencial antígeno (Ratanji, et al., 2014).

En cuanto al perfil de subclases de IgG, los anticuerpos antiinsulínicos presentes en los sueros del grupo tratado con la mezcla de insulina regular y NPH fueron predominantemente de la subclase IgG3 (Figura 3D). Aunque este resultado coincide con reportes previos, en los cuales se detectó esta subclase en anticuerpos antiinsulínicos (Andersen, 1976; Soto, et al., 1991), es importante mencionar que no se ha reportado la IgG3 como predominante, ya que en los artículos consultados se señala que la subclase IgG1 como la dominante, seguida por la IgG3 y la IgG4 y, en menor concentración, la IgG2 (Andersen, 1976; Koch, et al., 1986). Las diferencias entre los perfiles según la subclase de IgG encontrados en el presente estudio y los de reportes previos podrían estar relacionadas con las diferencias en la etiología de la diabetes mellitus de tipo 1 y la de tipo 2, teniendo en cuenta que el perfil de IgG reportado anteriormente se evaluó en pacientes con diabetes tipo 1 y en este estudio se evaluó en pacientes con diabetes tipo 2. Asimismo, llama la atención que el único grupo experimental en el que se observó una prevalencia de la subclase IgG3 fue el grupo tratado con la mezcla de insulina regular y NPH, lo cual podría estar relacionado con la posible formación de neoepítopes en dicha mezcla o con características propias de este grupo experimental. Entre las propiedades de la subclase IgG3 se ha descrito su producción como respuesta al estímulo de antígenos proteínicos (Devey, 1988) y su gran eficiencia en la activación de la vía $\mathrm{C} 1$ del complemento (Jefferis, et al., 1990). En cuanto a la importancia clínica de los niveles altos de IgG3, esta se ha reportado como la subclase predominante para los anticuerpos anti-Rh conjuntamente con la IgG1 en la enfermedad hemolítica del recién nacido, asociada con una mayor gravedad de la enfermedad, dada su capacidad de activar eficientemente el complemento (Urbaniak, et al., 1980). Teniendo en cuenta lo descrito, la presencia de anticuerpos antiinsulínicos con la subclase IgG3 podría potenciar la respuesta inmunitaria frente a la insulina NPH en individuos tratados con esta y con la regular. La prevalencia de IgG3 en los sueros del grupo tratado con la mezcla de insulina regular y NPH es interesante debido a las características biológicas de esta subclase, por lo cual sugerimos evaluarla en un grupo experimental con mayor número de individuos, que permita confirmar la prevalencia de este fenómeno en la población tratada con insulina regular y NPH.

La ausencia de complejos inmunitarios en las muestras de suero de los grupos experimentales es compatible con estudios previos en los que los niveles del complejo de anticuerpos antiinsulínicos e insulina exógena en sueros de pacientes bajo tratamiento con insulina no han sido diferentes a los observados en los sueros de pacientes con diabetes tipo 2 sin tratamiento o en los de los controles. La ausencia de complejos inmunitarios en las muestras evaluadas puede deberse a su formación inexistente o escasa en condiciones naturales, o a la gran efectividad del proceso natural de depuración. Sin embargo, no puede descartarse que dichos complejos sí se estén formando y puedan estar localizados o precipitados en lugares que no se analizaron en este estudio, como tampoco que luego de haberse formado hayan sido eliminados. Según los resultados obtenidos en el presente estudio puede sugerirse que la administración de la insulina no tiene un ningún papel, o muy poco, en la formación de complejos inmunitarios en pacientes con diabetes tipo 2 (Ratanji, et al., 2014). Esto contrasta con los resultados de un estudio en 237 pacientes con diabetes tipo 2 tratados con insulina durante más de un año, en quienes la presencia de los complejos inmunitarios se correlacionó con los niveles de anticuerpos antiinsulínicos pero no con las microangiopatías (Di Mario, et al., 1983). En este sentido, los datos aquí reportados son novedosos, ya que evalúan la presencia de complejos inmunitarios constituídos por anticuerpos antiinsulínicos e insulina exógena de manera individual frente a cada insulina analizada gracias al uso de anticuerpos de captura específicos para cada formulación (anti-regular, anti-NPH y anti-glargina). Además, debe tenerse en cuenta que, hasta el momento, la formación de complejos inmunitarios con insulinas humanas recombinantes y análogos de la insulina no se ha estudiado suficientemente.

\section{Conclusión}

Los resultados del estudio permiten concluir que existen diferencias en el perfil inmunogénico humoral (reactividad frente a la subclase de $\mathrm{IgG}$ ) de las tres insulinas exógena evaluadas, y sugerir que las modificaciones en la estructura proteínica de las insulinas, tales como los cambios en la secuencia de aminoacidos (glargina) o en su formulación o la presencia de excipientes (la protamina en la insulina NPH), inducen variaciones en el potencial inmunogénico de cada proteína terapéutica. Aunque la presencia de anticuerpos antiinsulínicos no se asoció con alteraciones de los parámetros metabólicos analizados en este estudio, los resultados obtenidos sugieren la importancia clínica de los anticuerpos antiinsulínicos, dada la prevalencia de la subclase IgG3 en el grupo tratado con las insulinas regular y NPH, subclase de inmunoglobulina que tiene la capacidad de activar eficientemente el complemento y favorecer la activación de los monocitos, potencializando de este modo la respuesta inmunitaria. Se requieren estudios posteriores que exploren el potencial biológico de estos hallazgos.

\section{Agradecimientos}

Los autores expresan sus más sinceros agradecimientos a los integrantes de los grupos de Investigación en Inmunotoxicología y de Farmacología de la Medicina Tradicional 
y Popular (FaMeTra), así como a la Fundación Instituto de Inmunología de Colombia (FIDIC), por su colaboración en la realización de la fase experimental de este trabajo.

\section{Contribución de los autores}

Yohana Domínguez Romero; Investigadora/estudiante de maestría a cargo del trabajo experimental; análisis y discusión de resultados y, redacción del artículo. Jorge Arturo Santa: Investigador; atención y selección de pacientes diabéticos. Luisa Fernanda Bohórquez: Investigadora; responsable de la atención y selección de pacientes diabéticos; análisis de resultados, revisión del artículo. Lucy Gabriela Delgado Murcia; Investigadora proponente del trabajo de investigación; análisis y discusión de resultados, revisión y aportes en la redacción del artículo; líder de la línea de inmunogenicidad de productos biotecnológicos y directora del Grupo de Investigación en Inmunotoxicología.

\section{Conflicto de intereses}

Los autores declaran no tener conflicto de intereses.

\section{Referencias}

American Diabetes Association (ADA). (2014) Standards of Medical Care in Diabetes. Diabetes Care. 37 (Supplement 1): S14-S80.

Asociación Latinoamericana de Diabetes (ALAD). (2013). Guías ALAD de diagnóstico control y tratamiento de la diabetes mellitus tipo 2. Fecha de consulta: 1 de junio de 2018. Disponible en: https://issuu.com/alad-diabetes/docs/ guias_alad_2013

Andersen, O. O. (1976). Clinical significance of anti-insulinantibodies. Acta Endocrinologica. 205: 231-40.

Berson, S. A., Yalow, R. S., Bauman, A., Rothschild, M. A., \& Newerly, K. (1956). Insulin-I131 metabolism in human subjects: demonstration of insulin binding globulin in the circulation of insulin treated subjects. The Journal of Clinical Investigation, 35 (2): 170-190.

Chen, J.-W., Frystyk, J., Lauritzen, T., \& Christiansen, J. S. (2005). Impact of insulin antibodies on insulin aspart pharmacokinetics and pharmacodynamics after 12-week treatment with multiple daily injections of biphasic insulin aspart 30 in patients with type 1 diabetes. European Journal of Endocrinology, 153 (6): 907-913.

Comisión de regulación en salud. (2011). Actualización de Plan Obligatorio de Salud. Bogotá. Pag.115

Devey, M. (1988). Clinical Aspects of IgG Subclasses and Therapeutic Implications. Immunology, 65 (2): 327.

Di Mario, U., Ventriglia, L., Iavicoli, M., Guy, K., \& Andreani, D. (1983). The correlation between insulin antibodies and circulating immune complexes in diabetics with and without microangiopathy. Clinical And Experimental Immunology, 52 (3): 575-580.

Dib, S. A., Freire, M. B., Miranda, W. L., \& Russo, E. M. (1994). Detection of insulin antibodies by radioassay and ELISA: interrelation and correlation with metabolic control in type I diabetes. Brazilian Journal of Medical and Biological Research, 27 (5): 1167-1180.
Domínguez Y. (2014). Inmunodetección de anticuerpos antiinsulina libres en suero $\mathrm{Y}$ unidos a la molécula de insulina en pacientes insulino-dependientes. Universidad Nacional de Colombia. Tesis. 46-48.

Eyzaguirre, F., \& Codner, E. (2006). [Insulin analogues: searching for a physiological replacement]. Revista Medica de Chile, 134 (2): 239-50.

Fineberg, S. E., Kawabata, T. T., Finco-Kent, D., Fountaine, R. J., Finch, G. L., \& Krasner, A. S. (2007). Immunological responses to exogenous insulin. Endocrine Reviews, 28 (6): 625-652.

Francis, A. J., Hanning, I., \& Alberti, K. G. M. M. (1985). The influence of insulin antibody levels on the plasma profiles and action of subcutaneously injected human and bovine short acting insulins. Diabetologia, 28 (6): 330-334.

Hattori, N., \& Shimatsu, A. (2013). Treatment with insulin glargine causes anti-insulin antibody production more frequently than other insulin analogs in patients with diabetes mellitus. Endocrine Reviews, 34 (3).

Heding, L. G., Marshall, M. O., Persson, B., Dahlquist, G., Thalme, B., Lindgren, F. Kaad, P. H. (1984). Immunogenicity of monocomponent human and porcine insulin in newly diagnosed Type 1 (insulin-dependent) diabetic children. Diabetologia, 27: 96-98.

Huber, R. (1980). Spatial structure of immunoglobulin molecules. Klinische Wochenschrift. 58 (22): 1217-1231

International Diabetes Federation. 2017. IDF Diabetes Atlas 2017. Fecha de consulta: 6 de junio de 2018. Disponible en: http://www.diabetesatlas.org

Irvine, W., Di Mario, U., Guy, K., Iavicoli, M., Pozzilli, P., Lumbroso, B., \& Andreani, D. (1978). Immune complexes and diabetic microangiopathy. Journal of Clinical \& Laboratory Immunology, 1 (3): 187-191.

Ishizuka, T., Ogawa, S., Mori, T., Nako, K., Nakamichi, T., Oka, Y., \& Ito, S. (2009). Characteristics of the antibodies of two patients who developed daytime hyperglycemia and morning hypoglycemia because of insulin antibodies. Diabetes Research and Clinical Practice, 84 (2): 21e-23e.

Itoh, A., Saisho, Y., Mitsuishi, M., Oikawa, Y., Kawai, T., Tanaka, M. (2011). Insulin glulisine may ameliorate nocturnal hypoglycemia related to insulin antibody - A case report. Diabetes Research and Clinical Practice. 94: e53-e54; discussion: e55.

Jefferis, R., \& Kumararatne, D. S. (1990). Selective IgG subclass deficiency: quantification and clinical relevance. Clinical and Experimental Immunology, 81 (3): 357-367.

Koch, M., François-Gérard, C., Sodoyez-Goffauxl, F., \& Sodoyez, J. C. (1986). Semi-quantitative assessment of antiinsulin total IgG and IgG sub-classes in insulin-immunized patients using a highly sensitive immunochemical micromethod. Diabetologia, 29 (10): 720-726.

Koyama, R., Nakanishi, K., Kato, M., Yamashita, S., Kuwahara, H., \& Katori, H. (2005). Hypoglycemia and hyperglycemia due to insulin antibodies against therapeutic human insulin: Treatment with double filtration plasmapheresis and prednisolone. American Journal of the Medical Sciences, 329 (5): 259-264.

Lahtela, J. T., Knip, M., Paul, R., Antonen, J., \& Salmi, J. (1997). Severe antibody-mediated human insulin resistance: Successful treatment with the insulin analog lispro: A case report. Diabetes Care, 20 (1): 71-73. 
Nyhan, D. P., Shampaine, E. L., Hirshman, C. A., Hamilton, R. G., Frank, S. M., Baumgartner, W. A., \& Adkinson, N. F. (1996). Single doses of intravenous protamine result in the formation of protamine-specific $\mathrm{IgE}$ and $\mathrm{IgG}$ antibodies. Journal of Allergy and Clinical Immunology, 97 (4): 991-997.

Ochoa R. (2012). Técnicas inmunoenzimáticas para ensayos clínicos de vacunas y estudios inmunoepidemiológicos. La habanaI. Finlay Ediciones. Pág. 14.

Pieber, T. R., Eugène-Jolchine, I., \& Derobert, E. (2000). Efficacy and safety of HOE 901 versus NPH insulin in patients with type 1 diabetes. Diabetes Care, 23 (2): 157-162.

Ratanji, K. D., Derrick, J. P., Dearman, R. J., \& Kimber, I. (2014). Immunogenicity of therapeutic proteins: Influence of aggregation. Journal of Immunotoxicology. 11 (2): 99-109.

Reeves, W. G., \& Kelly, U. (1982). Insulin antibodies induced by bovine insulin therapy. Clinical and Experimental Immunology, 50 (1): 163-170.

Schernthaner, G., Borkenstein, M., Fink, M., Mayr, W. R., Menzel, J., \& Schober, E. (1983). Immunogenicity of human insulin (Novo) or pork monocomponent insulin in HLA-DR-typed insulin-dependent diabetic individuals. Diabetes Care, 6 (Suppl. 1): 43-48.

Segal, T., Webb, E. A., Viner, R., Pusey, C., Wild, G., \& Allgrove, J. (2008). Severe insulin resistance secondary to insulin antibodies: Successful treatment with the immunosuppressant MMF. Pediatric Diabetes, 9 (3PART1): 250-254.

Sodoyez-Goffaux, F., Koch, M., Dozio, N., Brandenburg, D., \& Sodoyez, J. C. (1988). Advantages and pitfalls of radioimmune and enzyme linked immunosorbent assays of insulin antibodies. Diabetologia, 31 (9): 694-702.

Soto A, Deshazo RD, Morgan JE, Mather P, Ibrahim G, Frentz JM, Lauritano AA. (1991). Total IgG and IgG subclass specific antibody responses to insulin in diabetic patients. Annals of Allergy, 67 (5): 499-503.
Thalange, N., Bereket, A., Jensen, L. B., Hiort, L. C., \& Peterkova, V. (2016). Development of Insulin Detemir/ Insulin Aspart Cross-Reacting Antibodies Following Treatment with Insulin Detemir: 104-week Study in Children and Adolescents with Type 1 Diabetes Aged 2--16 Years. Diabetes Therapy, 7 (4): 713-724.

Urbaniak SJ, \& MA, G. (1980). ADCC (K-cell) lysis of human erythrocytes sensitized with rhesus alloantibodies. III. Comparison of IgG anti-D agglutinating and lytic (ADCC) activity and the role of IgG subclasses. British Journal of Haematology, 46 (3): 447-53.

Vajo, Z., Fawcett, J., \& Duckworth, W. C. (2001). Recombinant DNA technology in the treatment of diabetes: Insulin analogs. Endocrine Reviews. 22: 706-717.

Valla, V. (2010). Therapeutics of Diabetes Mellitus: Focus on Insulin Analogues and Insulin Pumps. Experimental Diabetes Research, 2010: 1-14.

Weiss, M. E., Nyhan, D. P., Peng, Z. K., Horrow, J. C., Lowenstein, E., \& Hirshman, C. A. (1989). Association of protamine $\operatorname{IgE}$ and $\mathrm{IgG}$ antibodies with life-threatening reactions to intravenous protamine. Anesthesia and Analgesia, 3 (4): 3-5.

Yanai, H., Adachi, H., \& Hamasaki, H. (2011). Diabetic ketosis caused by the insulin analog aspart-induced anti-insulin antibody: Successful treatmentwith the newest insulin analog glulisine. Diabetes Care. 34: 108-e108.

Zhao, T. Y., Li, F., \& Xiong, Z. Y. (2010). Frequent reoccurrence of hypoglycemia in a type 2 diabetic patient with insulin antibodies. Molecular Diagnosis and Therapy, 14 (4): $237-241$ 